\title{
Testing the direct-access model: GOD does not prime DOG
}

\author{
LAREE A. HUNTSMAN \\ San Jose State University, San Jose, Califormia
}

\begin{abstract}
In three repetition priming experiments that employed identical (e.g., DOG-DOG) and reversed repetitions (e.g., GOD-DOG), it was found that relative to controls (e.g., DOG-DOG), GOD-type words did not prime DOG-type words. Also, neither DUT-type nor TUD-type nonwords primed DUT-type nonwords. In Experiments 1 and 2, these results occurred using both long- and short-term repetition priming conditions, respectively. In Experiment 3, the word results held under conditions of short-term priming coupled with stimulus misorientation. However, the nonword results resembled the word results (i.e., identical but not reversed repetitions primed nonwords). The failure to provide explicit evidence for direct visual access (e.g., GOD does not prime DOG while DOG does) irrespective of other sources of lexical activation supports theories of word recognition that postulate multiple and varied lexical representations that are activated through a matrix of connections.
\end{abstract}

Most theories of word recognition agree that the process of reading includes both orthographic (i.e., how words look) and phonological (i.e., how words sound when spoken aloud) sources of lexical activation. However, there is disagreement among these theories with respect to the relative importance, the degree of independence, and the time course of orthographic and phonological sources of lexical activation.

According to direct-access theories of word recognition, the orthographic representation of a printed word activates its lexical entry directly with minimal, if any, use of phonology (see, e.g., Aaronson \& Ferres, 1983; Baron, 1973; Becker, 1976, 1980; Bower, 1970; Forster \& Chambers, 1973; Frederiksen \& Kroll, 1976; Goodman, 1969; Green \& Shallice, 1976; Huey, 1908; Kolers, 1970; Martin \& Jensen, 1988; Smith, 1971). Conversely, phonological activation theories of word recognition contend that printed words are prelexically recoded into a phonological representation. Because recoding occurs via the application of spelling-sound conversions of orthographic elements within the words, phonological representations play an early role in activating lexical entries prior to recognition (see, e.g., Bloomfield, 1942; Corcoran, 1966; Gib-

\footnotetext{
Preparation of this report was supported in part by a San Jose State University Psychology Department Research Grant. Additional support was provided by National Aeronautics and Space Administration Cooperative Agreement NCC 2-327 and NCC 2-798 to Kevin Jordan. I thank Sepideh Dadras and Joseph Tajnai for their assistance with stimulus development, Meredith Brown, Rigoberto Gutierres, Melanie Hein, Todd Moore, Jennifer Skinner, Kenneth Smith, and Juanita Traver for their tireless assistance with data collection, and especially Guy Woffind in for his invaluable programming assistance. I also thank Joanne Miller, Guy Van Orden, and an anonymous reviewer for their helpful comments on earlier versions of this report. Correspondence should be addressed to L. A. Huntsman, Department of Psychology, San Jose State University, San Jose, CA 95192-0120 (e-mail: huntsman(a)email.sjsu.edu).
}

son, 1970; Gough, 1972; Hansen \& Rodgers, 1968; Hillinger, 1980; Inhoff \& Topolski, 1994; Lesch \& Pollatsek, 1993; Lukatela, Lukatela, \& Turvey 1993; Lukatela \& Turvey, 1993, 1994a, 1994b; Rubenstein, Lewis, \& Rubenstein, 1971; Spoehr \& Smith, 1973; Van Orden, 1987; Van Orden, Johnston, \& Hale, 1988; Van Orden, Pennington, \& Stone, 1990).

Dual-access theories posit that both phonological and orthographic sources of lexical activation are involved in word recognition. These theories describe a process in which the simultaneous activation of phonological and orthographic sources of information results in word recognition. However, according to dual-access theorists, the phonological activation occurs at a slower rate than the orthographic activation (e.g., Coltheart, 1978; Coltheart, Davelaar, Jonasson, \& Besner, 1977; Davelaar, Coltheart, Besner, \& Jonasson, 1978; McClelland \& Rumelhart, 1981; Meyer \& Ruddy, 1973; Norris \& Brown, 1985; Seidenberg, 1985; Seidenberg, Waters, Barnes, \& Tanenhaus, 1984; Stanovich \& Bauer, 1978; Waters, Seidenberg, \& Bruck, 1984). Some dual-access theorists, such as Carr and Pollatsek (1985), postulate that orthographic and phonological sources of lexical activation are cooperative, rather than independent, so that both sources contribute to the word recognition process.

Hybrids of the dual-access models include verification processes in word identification (Becker, 1980; Grossberg \& Stone, 1986; Paap, Newsome, McDonald, \& Schvaneveldt, 1982; Van Orden, 1987). Verification theorists place "intralexical" orthographic checkpoints between prelexical and postlexical processes. Van Orden's is the most popular; he has posited that during lexical access, phonological features covary with orthographic features. Specifically, word identification begins prelexically with phonological mediation and then proceeds intralexically with a verification (spelling check) of the word's orthographic features and ends postlexically with word identification. 


\section{Repetition Priming Research}

One method that may be used to examine lexical organization utilizes the repetition priming procedure (Forbach, Stanners, \& Hochhaus, 1974; Scarborough, Cortese, \& Scarborough, 1977; Stanners, Neiser, Hernon, \& Hall, 1979). In this procedure, words and nonwords are presented twice for a lexical decision judgment. The first presentation of the letter string is known as the prime and the second presentation is known as the target. The lag, which is the number of intervening trials between the prime and the target, will vary depending on whether researchers are interested in long-term repetition priming (a lag of approximately 16 items) or short-term repetition priming (a lag of approximately 4 items) (see Kirsner \& Dunn, 1985; Monsell, 1985, 1987; Ratcliff, Hockley, \& McKoon, 1985; Scarborough et al., 1977). Word recognition has been found to be sensitive to the variation in the similarity of recent events. A single presentation of a prime stimulus has been found to enhance the speed and accuracy of subsequent lexical decision response latencies to a target stimulus. This result is known as the repetition priming effect.

In the repetition priming effect, it is assumed that the presentation of a word induces activation of that word's lexical representation (Forbach et al., 1974; Monsell, 1985; Morton, 1979; Stanners, Neiser, Hernon, \& Hall, 1979; Stanners, Neiser, \& Painton, 1979). This increased activation of the word's lexical representation makes it more accessible when the same word is repeated as a target. The following sections present major lines of evidence supporting orthographic and phonological activation utilizing the repetition priming procedure.

Orthographic/morphological repetition effects. A large body of evidence indicates that repetition priming effects arise from the shared orthographic and morphological relationship between primes and targets (e.g., HEALTH-HEAL) and that a purely orthographic, or formedbased, relationship between primes and targets (e.g., CAR-CARD) is not sufficient information in and of itself to produce repetition priming effects (see Feldman \& Moskovljevic, 1987; Fowler, Napps, \& Feldman, 1985; Hanson \& Wilkenfeld, 1985; Kirsner, Dunn, \& Standen, 1987; Lima, 1987; Murrell \& Morton, 1974; Napps, 1985; Napps \& Fowler, 1987; Stanners, Neiser, Hernon, \& Hall, 1979; Stanners, Neiser, \& Painton, 1979). For example, the repetition priming effect has been found to occur when the morphologically related prime and target have marginal differences in pronunciations or spellings (e.g., HEALTH-HEAL; Fowler et al., 1985; Hanson \& Wilkenfeld, 1985). A study by Stanners, Neiser, and Painton (1979) revealed that both prefixed and stem forms of words (e.g., UNAWARE and AWARE, respectively) facilitated response latencies to subsequent presentations of base word targets (e.g., AWARE). These researchers showed that using both inflected and base word forms of words (e.g., WALKING and WALK, respectively) produced the repetition priming effect in subsequent presentations of base words (e.g., WALK). Similarly, Fowler et al. found that both inflected (e.g., MANAGES) and derived (e.g., MANAGEMENT) forms of words produced the repetition priming effect in subsequent presentations of base words (e.g., MANAGE). Lima (1987) further found that prefixed word primes (e.g., DISHONEST and DISFIGURED) facilitated response latencies to subsequent presentations of stem targets (e.g., HONEST and FIGURED).

If these morphological priming effects occur because of the shared orthographic relationships among the primes and targets, repetition priming effects would be expected to also occur among morphologically unrelated words that share orthographic properties (e.g., RIBBONRIB). However, repetition priming effects have not been found to occur among morphologically unrelated words that share orthographic properties (Hanson \& Wilkenfeld, 1985; Napps, 1985; Napps \& Fowler, 1987). Similarly, Lima (1987) observed that word primes that contained pseudoprefixes (e.g., SUBLIME) and word primes that contained pseudostems (e.g., ARSON) did not significantly facilitate response latencies to subsequent presentations of orthographically similar word targets (e.g., LIME and SON). The results of these studies suggest that repetition priming effects are a function of the morphological relationship between primes and targets as opposed to the orthographic relationship between primes and targets.

Phonological repetition effects. A number of experiments employing numerous variations of the repetition priming procedure have produced evidence illustrating that the phonological structure of a word affects its processing (Hillinger, 1980; Humphreys, Evett, \& Taylor, 1982; Kirsner \& Dunn, 1985; Lukatela et al., 1993; Lukatela \& Turvey, 1991; Masson \& Freedman, 1990; Meyer, Schvaneveldt, \& Ruddy, 1974). The often-cited experiment conducted by Meyer et al. (1974) yielded evidence for phonological activation by manipulating the rhyming relationship between pairs of letter strings. Using a twoitem lexical decision task, Meyer et al. (1974) found that decision latencies were somewhat facilitated by word pairs that were orthographically and phonologically similar (e.g., BRIBE--TRIBE), but that lexical decisions were significantly inhibited by word pairs that were orthographically similar yet phonologically dissimilar (e.g., $\mathrm{COUCH}-$ TOUCH). Hillinger added to these findings by showing rhyme priming effects to be independent of orthographic similarity. In particular, Hillinger found equivalent facilitation for orthographically similar and dissimilar primetarget pairs (e.g., EIGHT-MATE). In explaining their results, these researchers suggested that the spelling-sound correspondence rules used in developing the phonological representation for the first word are also applied to the second, resulting in shorter latencies for the rhyming pairs and longer latencies for the nonrhyming pairs. Masson and Freedman showed that naming latencies to word targets (e.g., CRUISE) were faster if the targets had previously appeared as orthographically dissimilar pseudohomophone primes (e.g., KROOZE) in the lexical decision task. Using both long and short stimulus onset asyn- 
chronies in a naming task, Lukatela and Turvey (1991) demonstrated that both associated pseudohomophones (e.g., TAYBLE) and associated words (e.g., TABLE) primed targets (e.g., CHAIR) relative to spelling control primes (e.g., TARBLE). Lukatela et al. (1993) found that in a naming task, both low-frequency homophones (e.g., TOWED) and high-frequency homophones (e.g., BEACH) primed pseudo-associated targets (e.g., FROG and TREE) relative to spelling control primes (e.g., TROD and BENCH).

Other studies using pattern masking and short stimulus onset asynchronies have yielded conflicting conclusions regarding the possibility of a phonological relationship between primes and targets. Using a repetition priming procedure in which primes were preceded and followed by a pattern mask, Humphreys et al. found a significant influence of homophone primes (e.g., MAID primed MADE) but not pseudohomophone primes (e.g., BLOO did not prime BLUE). Interestingly, participants were almost never aware of the priming word but were significantly facilitated in their report of the target word when the primes were homophones but not pseudohomophones. Martin and Jensen (1988) examined whether rhyme priming from orthographically dissimilar primes is an automatic or strategic process. A short stimulus onset asynchrony was used to prevent participants from using phonological strategies when silently reading primes or responding to targets. Primes were presented for $200 \mathrm{msec}$ before the target was presented for a lexical decision judgment either 50 or $350 \mathrm{msec}$ later. Results indicated that brief exposure to primes produced no evidence of rhyme priming in target response latencies for orthographically similar prime-target pairs (e.g., FOOL-SPOOL) or orthographically dissimilar prime-target pairs (e.g., RULE-SPOOL) when compared with neutral control prime-target pairs (e.g., XXXXX-SPOOL). As can be seen from the above review, studies showing that phonological codes play a tole in word recognition have been both affirmed and denied throughout various experimental literature on the topic. What cannot be seen from the available body of empirical evidence, however, are studies indicating that orthographic codes perform a solo role in the word recognition process.

Testing the direct-access model. Although there is little empirical evidence explicitly supporting direct visual access by eliminating the possibility of phonological activation in word recognition, many theories continue to downplay the significant role that phonology plays in word recognition. When a phonological manipulation fails to affect word recognition, it is interpreted as support that word recognition proceeds primarily by the direct visual route (see Fleming, 1993; Jared \& Seidenberg, 1991; Seidenberg, 1992). But when a phonological manipulation succeeds in affecting word recognition, it is interpreted as support for dual-access routes (see Coltheart, 1978; Coltheart et al., 1977; Davelaar et al., 1978; McClelland \& Rumelhart, 1981; Meyer \& Ruddy, 1973; Norris \& Brown, 1985; Seidenberg, 1985; Seidenberg et al., 1984; Stano- vich \& Bauer, 1978; Waters et al., 1984). This suggests that the direct-access model is, more often than not, supported by default rather than by direct empirical evidence. Perhaps the traditional method for postulating mechanisms of word recognition should be reversed. Phonological theorists have defended their position well and have stressed that explicit, unambiguous evidence has been provided in support of phonological activation hypotheses. They have also challenged direct-access theorists to provide a demonstration of direct visual access that is distinguishable from phonological activation (see related discussions in Bauer \& Stanovich, 1980; Besner, Davies, \& Daniels, 1981; Carello, Turvey, \& Lukatela, 1992; Glushko, 1981; Lukatela et al., 1993; McCusker, Hillinger, \& Bias, 1981; Van Orden, 1987; Van Orden et al., 1990).

Phonological activation was demonstrated when participants of a Van Orden (1987) experiment showed larger false positive error rates when they responded to stimulus foils that were homophonic to category exemplars (e.g., ROWS for the A FLOWER category) than when they responded to nonhomophonic nonword foils that had been equated for orthographic similarity (e.g., ROBS for the A FLOWER category). Jared and Seidenberg (1991) countered Van Orden's positive phonology effect with the negative phonology effect that Rows was not falsely categorized as A LIVING THING. Stated differently, Jared and Seidenberg presented a negative phonology effect as evidence that, under certain circumstances, phonological activation does not always occur; so, the conclusion is that word recognition must proceed primarily by the direct visual route. The logic used by Jared and Seidenberg in their claim that negative phonology effects provide evidence for direct access can be used to test the direct-access model. For instance, if the orthographic representations of visually presented words are assembled rapidly and automatically in lexical access, then words that share the same letters but are phonologically and morphologically unrelated should induce similar lexical activity. For example, words such as GOD and DOG share the same letters (albeit in reverse order). If phonemic identity is defined as position sensitive, then GOD and DOG are phonologically unrelated by two out of three letters. Most certainly, GOD and DOG are morphologically unrelated, however. If relative to controls (e.g., DOG-DOG), GOD-type words prime DOG-type words because of orthographic similarity, there should be no difference in the repetition priming effect for identical and reversed repetitions. The GOD-DOG priming effect would provide a demonstration of direct visual access that is uncontaminated by morphological and phonological sources of activation. In the same manner, if relative to controls (e.g., DUT-DUT), TUD- type nonwords prime DUT-type nonword targets, this would indicate that when phonological attributes are controlled for, since nonwords cannot be morphologically related, orthographic representation is a sufficient source of lexical activation. 
Another motivating factor behind the suggestion that GOD may prime DOG comes from the behavior of acquired dyslexics. Patients who have experienced extensive cortical damage sometimes incorrectly identify a stimulus word that is similar in form. For instance, the deep dyslexic may incorrectly name the word SAW as WAS, NOT as TON, or ON as NO (see Huston, 1992; Marshall \& Newcombe, 1973, 1980; Orton, 1925; Shallice \& Warrington, 1975, 1987). Although there are a variety of acquired dyslexia syndromes, it is generally agreed that the behavior caused by dyslexia results from damage to one or more of the routes (i.e., orthographic, phonological, and semantic) by which words are retrieved from lexical memory (Coltheart, 1980, 1985; Friedman, 1995; Marshall \& Newcombe, 1973, 1980; Shallice \& Warrington, 1987). In addition, these theorists consider the orthographic route to be the direct route (i.e., preferred) and the phonologic and semantic routes to be indirect routes (i.e., secondary) to lexical memory. Therefore, the SAW-named-as-WAS error is viewed as evidence of the existence of a direct visual route to lexical access. Deep dyslexics would name SAW as WAS because the damage that caused the dyslexia obliterated almost all of the access routes, including letter position, leaving only the letter identity route to aid lexical access. Since letter position is thought to be separate from letter identity, the subtractive effects of the damage result in the SAW-named-as-WAS error.

The logic by which direct access can sometimes use letter identity independent of letter position suggests that GOD may prime DOG. A GOD-DOG priming effect would be evidence for direct access, whereas a null GOD-DOG priming effect would be evidence against direct access. After all, if the SAW-WAS error of visual dyslexics is used as evidence that direct access occurs, it is only fair that a negative GOD-DOG priming effect be used as evidence that direct access does not always occur (see related discussion in Van Orden et al., 1990). In other words, the present experiments were designed so that models other than direct access are supported by default rather than by direct empirical evidence. Therefore, the "good effort" criterion for accepting the null hypothesis, as postulated by Frick (1995), will be followed. With this in mind, the above-mentioned rationale makes a test of the null hypothesis possible (e.g., if GOD does not prime DOG while DOG does, it is likely that lexical access requires more than a direct-access route based on orthography). In addition, three experiments were designed so that the results would not rely on a single null effect but rather on three conceptual replications providing converging results. In Experiments 1 and 2, the long- and short-term repetition priming procedures were used, respectively. Since the most readily available codes predominate under conditions of stimulus degradation (Sternberg, 1969; Van Orden, 1987), the short-term priming procedure coupled with stimulus degradation was employed in Experiment 3. In this manner, the three experiments put forth a good effort to find an effect of direct access that is dis- tinguishable from other sources of lexical information but that also makes the null hypothesis a distinct possibility.

\section{EXPERIMENT 1}

\section{Method}

Participants. Forty-eight undergraduates from San Jose State University participated for course credit. All participants were righthanded, native speakers of English, and all had normal or correctedto-normal vision.

Materials. Experimental word stimuli consisted of 36 critical word pairs that were reversed versions of each other. For example, GOD is DOG spelled backward. The mean frequency of the words was 41 per million (Kučera \& Francis, 1967; range $=1-500$ ). Since it was not possible to match the word pairs on frequency, word frequency was distributed evenly across conditions. Experimental nonword stimuli consisted of 36 orthographically legal (i.e., pronounceable) nonword pairs. The nonword pairs were also reversed versions of each other. For example, TUD is DUT spelled backward. The sets of words and nonwords were matched on length $(M=3.36$ letters, range $=3-5$ ). Filler items were used to maintain appropriate lags between primes and targets and to avoid inducing processing strategies. Filler stimuli consisted of 60 content words of moderate frequency and 60 pronounceable, orthographically legal nonwords that were not homophonic with any English word. (See Appendices A and B for a complete list of stimulus items.)

Design. In each part of the experiment, four counterbalanced lists were constructed containing 264 items consisting of 72 primes, 72 targets, and 120 filler items. Lists were designed so that each member of the critical pair served as a prime and as a target. Specifically, lists containing 72 yoked quadruplets were constructed in such a way that each word target was preceded by the same word primes in two of the lists (e.g., GOD-GOD and DOG-DOG) and the reversed word primes in two of the lists (e.g., GOD-DOG and DOG-.. GOD). Each nonword target was also preceded by the same nonword primes in two of the lists (e.g., DUT-DUT and TUD-TUD) and the reversed nonword primes in two of the lists (e.g., DUT-rUD and TUD-DUT). Each participant saw only one prime-target pair of the quadruplet. Since each participant was presented with 18 experimental items of each word and nonword type across each set of 4 participants, all members of each quadruplet appeared equally often. Equal numbers of positive trials and negative trials were used to discourage response bias strategies.

The mean lag between the presentation of the prime and the target was eight items. Lags ranged from 5 to 11 and were evenly distributed around a lag of 8 . Filler items were used to maintain appropriate lags and to avoid inducing processing strategies. A quarter of the participants were randomly assigned to each list. Forty-eight different lists were constructed by a computer program (Woffindin, 1995) that was designed to ensure an even distribution of the primetarget conditions, the number of intervening trials between primes and targets, the string length, the word frequency, and the sequential dependencies of word and nonword trials. To summarize the 2 (word, nonword) $\times 4$ (prime-target condition) experimental design, across lists each target word and each nonword were preceded by their primes in identical and reversed form.

Apparatus. Stimulus strings were displayed one at a time in lowercase letters on a computer monitor. Letters were white on a black background. An IBM-compatible microcomputer equipped with a World Commerce Psycholinguistic Testing Station controlled the experiment and recorded response latencies. A comfortable viewing distance was chosen by each participant. The average letter string subtended a visual angle of approximately $2^{\circ}$. The response box contained three buttons, one for initiating trials and two for indicating lexical decision responses. 
Procedure. The pacing of trials was controlled by the participant. At the start of each trial, a fixation asterisk $\left({ }^{*}\right)$ appeared at the center of the screen. To initiate a trial, the participant used both thumbs to press a button centered on the lower half of the response box, causing the asterisk to disappear. The letter string then appeared in the center of the screen $350 \mathrm{msec}$ later and remained there until the participant made his/her response. Responses were made by pressing one of two buttons on the upper half of the response box with the appropriate index finger. The left-hand button was used for nonword responses and the right-hand button for word responses. Response feedback was provided in the form of a beep whenever an error was committed. The instructions stressed both speed and accuracy by asking participants to "work as quickly as possible without making a lot of mistakes."

Each participant completed 30 practice trials before proceeding to the 264 experimental trials. The practice items consisted of words and nonwords not appearing elsewhere in the experiment. The experimental session lasted approximately $30 \mathrm{~min}$ for each participant.

Scoring of data. Response time data from incorrect trials were excluded from the latency analyses. The occasional extremely long response time (i.e., more than $2.5 S D$ greater than the participant's mean for a particular type of trial) was replaced by the cutoff value of $2.5 S D$ plus the participant's mean for that trial type. If the lexical decision response latencies for a participant yielded a grand mean greater than $1,000 \mathrm{msec}$, that participant's data were eliminated from all analyses. Data sets for participants and for stimulus items were computed from the response latency and error rate data. In the subject analysis of variance $\left(F_{1}\right)$, two data sets were formed by computing mean response latencies and error rates over stimulus items for each participant. In the item analysis of variance $\left(F_{2}\right)$, two data sets were formed by computing mean response latencies and error rates over participants for each stimulus item.

\section{Results}

Prime and target examples, mean lexical decision response times (in milliseconds), percentage error (PE), and repetition priming effects for words are presented in Table 1. Presented in Table 2 are prime and target examples, mean lexical decision response times, $\mathrm{PE}$, and repetition priming effects for nonwords. All descriptive statistics reported were derived from the subject analyses.

Word results. Analyses indicated that identical primes (e.g., the first occurrence of DOG in the DOG-DOG pair) and reversed primes (e.g., the occurrence of GOD in the GOD-DOG pair) did not differ significantly from each other (799 msec for identical primes and $792 \mathrm{msec}$ for reversed primes, $F_{1}<1$ and $F_{2}<1$ ). However, targets primed by identical repetitions ( $732 \mathrm{msec}$ for the second occurrence of DOG in the DOG-DOG pair) were significantly faster

Table 1

Experiment 1 Prime and Target Examples, Mean Lexical Decision Response Times (in Milliseconds), Error Rates (in Percentages), and Repetition Priming Effects for Words

\begin{tabular}{lccc}
\hline & $\begin{array}{c}\text { Control } \\
\text { Prime Example }\end{array}$ & $\begin{array}{c}\text { Target Primed by } \\
\text { Identical Word }\end{array}$ & $\begin{array}{c}\text { Target Primed by } \\
\text { Reversed Word }\end{array}$ \\
\hline Prime & DOG & DOG & GOD \\
Target & & DOG & DOG \\
Response times & 796 & 732 & 783 \\
Priming effect & & $64^{*}$ & 13 \\
Error rates & 9.96 & 6.70 & 7.29 \\
Priming effect & & 3.26 & 2.67 \\
\hline
\end{tabular}

*Significant repetition priming effect.
Table 2

Experiment 1 Prime and Target Examples, Mean Lexical Decision Response Times (in Milliseconds), Error Rates (in Percentages), and Repetition Priming Effects for Nonwords Control Target Primed by Target Primed by Prime Example Identical Nonword Reversed Nonword

\begin{tabular}{lcrr}
\hline Prime & DUT & DUT & TUD \\
Target & & DUT & DUT \\
Response times & 809 & 794 & 799 \\
Priming effect & & 15 & 10 \\
Error rates & 12.65 & 9.17 & 9.78 \\
Priming effect & & 3.48 & 2.87 \\
\hline
\end{tabular}

than targets primed by reversed repetitions $[783 \mathrm{msec}$ for the occurrence of DOG in the GOD-DOG pair; $F_{1}(1,47)=$ $27.53, p<.001$ and $\left.F_{2}(1,17)=22.83, p<.001\right]$. Analyses also revealed a significant interaction between primes and targets on response latencies $\left[F_{1}(1,47)=20.27, p<\right.$ .001 and $\left.F_{2}(1,17)=17.56, p<.001\right]$.

Since DOG-TYPE and GOD-TYPE primes did not differ significantly, they were combined to simplify further analyses $(M=796 \mathrm{msec})$. In the assessment of specific repetition priming effects, the base word prime condition (e.g., the first occurrence of DOG in the DOG-DOG pair) served as a control condition that was compared with the base word target condition (e.g., the second occurrence of DOG in the DOG-DOG pair) and the critical target conditions (e.g., DOG primed with GOD). The difference in mean response latency between the base word prime condition and the base word target condition indicates the identical priming effect (see Table 1). Planned comparisons showed that targets (e.g., DOG) were facilitated by identical primes (e.g., DOG) but not by reversed primes (e.g., GOD). The identical priming effect $(64 \mathrm{msec})$ was statistically significant for response latencies $\left[F_{1}(1,95)=87.26, p<.001\right.$ and $\left.F_{2}(1,17)=28.34, p<.001\right]$. Response latencies to targets were not significantly facilitated $(13 \mathrm{msec})$ by reversed primes $\left[F_{1}(1,95)=2.83, p>.05\right.$ and $\left.F_{2}<1\right]$. With respect to the error rate data, no significant effects were noted.

Nonword results. Analyses showed that identical primes (e.g., the first occurrence of DUT in the DUT-DUT pair) and reversed primes (e.g., the occurrence of TUD in the TUD-DUT pair) did not differ significantly from each other [ $801 \mathrm{msec}$ for identical primes and $816 \mathrm{msec}$ for reversed primes; $F_{1}(1,47)=1.52, p>.05$ and $\left.F_{2}<1\right]$. Likewise, targets primed by identical repetitions ( $794 \mathrm{msec}$ for the second occurrence of DUT in the DUT-DUT pair) were not significantly faster than targets primed by reversed repetitions ( $799 \mathrm{msec}$ for the occurrence of DUT in the TUD-DUT pair; $F_{1}<1$ and $\left.F_{2}<1\right)$. Analyses did not reveal a significant interaction between primes and targets on response latencies $\left[F_{1}(1,47)=1.40, p>.05\right.$ and $\left.F_{2}<1\right]$.

Since DUT- and TUD-type primes did not differ significantly, they were combined to simplify further analyses $(M=809 \mathrm{msec})$. In the assessment of specific repetition priming effects, the base word prime condition (e.g., the first occurrence of DUT in the DUT-DUT pair) served as a control condition that was compared with the base word 
target condition (e.g., the second occurrence of DUT in the DUT-DUT pair) and the critical target conditions (e.g., DUT primed with TUD). In this assessment, the difference in mean response latency between the base word prime condition and the base word target condition indicates the identical priming effect (see Table 2). Although in the right direction, planned comparisons showed that targets (e.g., DUT) were not significantly facilitated by identical primes (e.g., DUT) or by reversed primes (e.g., TUD). Specifically, neither the identical priming effect $(15 \mathrm{msec})$ nor the reversed priming effect $(10 \mathrm{msec})$ was statistically significant for response latencies $\left(F_{1}<1\right.$ and $F_{2}<1$, respectively). With respect to the error rate data, no significant effects were noted.

\section{Discussion}

If the orthographic codes of visually presented words are indeed assembled rapidly and automatically for use in lexical access, words that share the same letters should induce similar lexical activity. GOD shares the same letters but is morphologically and phonologically unrelated to DOG. The results indicate that, relative to controls (e.g., DOG-DOG), GOD-type words did not prime DOG-type words.

Likewise, if the orthographic codes of visually presented words operate directly, nonwords that share the same letters should induce similar lexical activity. Stated differently, it should not matter whether identical or reversed nonwords are used as primes. The present results show that neither identical (e.g., DUT-DUT) nor reversed (e.g., DUT-TUD) repetitions primed nonword targets. Therefore, for nonwords, it appears that when morphological elements (as in the identical priming condition) and phonological and morphological elements (as in the reversed priming condition) are controlled for, orthographic representation is not always a sufficient source of lexical activation. However, the 15 -msec identical priming effect observed in the nonwords, although insignificant, was in the predicted direction for direct access. The priming that did occur is most likely a reflection of orthographic and phonological effects since nonwords cannot share a morphological relationship. For instance, the nonword TUD is not morphologically related to TUD because TUD has no meaning; however, TUD looks and sounds like TUD.

\section{EXPERIMENT 2}

The aim of Experiment 2 was to enhance the negligible repetition priming effects found for reversed word primes (i.e., GOD did not prime DOG), identical nonword primes (i.e., TUD did not prime TUD), and reversed nonword primes (i.e., TUD did not prime DUT) of Experiment 1 by employing the short-term repetition priming procedure. It is possible that the null GOD-DOG priming effect of Experiment 1 resulted from the limited longevity of lexical activation (Monsell, 1985; Ratcliff et al., 1985). Previous research has suggested that some prime-target effects that are produced under conditions of close temporal succession are not produced under conditions of long temporal succession (see Bradshaw \& Nettleton, 1974; Hanson \& Wilkenfeld, 1985; Kirsner et al., 1987; Meyer et al., 1974; Monsell, 1985, 1987; Napps, 1985; Napps \& Fowler, 1987; Scarborough et al., 1977; Scarborough, Gerard, \& Cortese, 1984). Although the average lag $(M=8)$ between the primes and targets used in Experiment 1 was half the lag employed in typical longterm priming studies $(M=16)$ (Kirsner \& Dunn, 1985; Monsell, 1985, 1987; Ratcliff et al., 1985; Scarborough et al., 1977), it is still possible that the lags were not short enough for lexical activation to survive. Therefore, in order to assess the possibility of a Type II beta error (i.e., the GOD-DOG priming effect was missed), Experiment 2 was a conceptual replication of Experiment 1 using an extremely short (average lag of 2 ) repetition priming procedure.

\section{Method}

Participants. The participants were 48 different undergraduates from the same population as those tested in Experiment 1.

Procedure and Design. Besides a change in the average lag between primes and targets, the method in Experiment 2 was the same as that of Experiment 1 .

Prime-target conditions. The mean lag between the presentation of the prime and the target was two items. Lags ranged from 0 to 4 and were evenly distributed around a lag of 2 . As in Experiment 1 , filler items were used to maintain appropriate lags and to avoid inducing processing strategies. A quarter of the participants were randomly assigned to each list.

\section{Results}

Prime and target examples, mean lexical decision response times (in milliseconds), PE, and repetition priming effects for words are presented in Table 3 . Presented in Table 4 are prime and target examples, mean lexical decision response times, $\mathrm{PE}$, and repetition priming effects for nonwords.

Word results. Analyses indicated that identical primes (e.g., the first occurrence of DOG in the DOG-DOG pair) and reversed primes (e.g., the occurrence of GOD in the GOD-DOG pair) did not differ significantly from each other (760 msec and 6.66 PE for identical primes and $759 \mathrm{msec}$ and 7.00 PE for reversed primes, $F_{1}<1$ and $F_{2}<1$ for response latencies and $F_{1}<1$ and $F_{2}<1$ for error rates). However, targets primed by identical repetitions $(696 \mathrm{msec}$ and $1.87 \mathrm{PE}$ for the second occurrence of DOG in the DOGDOG pair) were significantly faster and less error prone

Table 3

Experiment 2 Prime and Target Examples, Mean Lexical Decision Response Times (in Milliseconds), Error Rates (in Percentages), and Repetition Priming Effects for Words

\begin{tabular}{lccc}
\hline & $\begin{array}{c}\text { Control } \\
\text { Prime Example }\end{array}$ & $\begin{array}{c}\text { Target Primed by } \\
\text { Identical Word }\end{array}$ & $\begin{array}{c}\text { Target Primed by } \\
\text { Reversed Word }\end{array}$ \\
\hline Prime & DOG & DOG & GOD \\
Target & & DOG & DOG \\
Response times & 760 & 696 & 744 \\
Priming effect & & $64^{*}$ & 16 \\
Error rates & 6.83 & 1.87 & 7.59 \\
Priming effect & & 4.96 & -.76 \\
\hline
\end{tabular}

* Significant repetition priming effect. 
Table 4

Experiment 2 Prime and Target Examples, Mean Lexical Decision Response Times (in Milliseconds), Error Rates (in Percentages), and Repetition Priming Effects for Nonwords

\begin{tabular}{lccc} 
& $\begin{array}{c}\text { Control } \\
\text { Prime Example }\end{array}$ & $\begin{array}{c}\text { Target Primed by } \\
\text { Identical Nonword }\end{array}$ & $\begin{array}{c}\text { Target Primed by } \\
\text { Reversed Nonword }\end{array}$ \\
\hline Prime & DUT & DUT & TUD \\
Target & & DUT & DUT \\
Response times & 778 & 760 & 776 \\
Priming effect & & 18 & 2 \\
Error rates & .76 & .45 & .51 \\
Priming effect & & .31 & .25 \\
\hline
\end{tabular}

than targets primed by reversed repetitions $[744 \mathrm{msec}$ and 7.59 PE for the occurrence of DOG in the GOD-DOG pair; $F_{1}(1,47)=28.31, p<.001$ and $F_{2}(1,17)=29.00$, $p<.001$ for response latencies, and $F_{1}(1,47)=48.67, p<$ .001 and $F_{2}(1,17)=9.09, p<.01$ for error rates]. Analyses also revealed a significant interaction between primes and targets on response latencies $\left[F_{1}(1,47)=5.12, p<.05\right.$ and $\left.F_{2}(1,17)=5.07, p<.05\right]$ and error rates $\left[F_{1}(1,47)=\right.$ $20.73, p<.001$ and $F_{2}(1,17)=6.09, p<.05$ ]

Since DOG- and GOD-type primes did not differ significantly, they were combined to simplify further analyses $(M=760 \mathrm{msec}$ and $6.83 \mathrm{PE})$. In the assessment of specific repetition priming effects (see Table 3 ), planned comparisons showed that targets (e.g., DOG) were facilitated by identical primes (e.g., DOG) but not by reversed primes (e.g., GOD). The identical priming effect $(64 \mathrm{msec}$ and $4.96 \mathrm{PE}$ ) was statistically significant for response latencies $\left[F_{1}(1,47)=54.09, p<.001\right.$ and $F_{2}(1,17)=29.00$, $p<.001]$ and error rates $\left[F_{1}(1,47)=68.70, p<.001\right.$ and $\left.F_{2}(1,17)=9.11, p<.01\right]$. Response latencies to targets were not significantly facilitated $(16 \mathrm{msec}$ and $-.76 \mathrm{PE})$ by reversed primes $\left[F_{1}(1,47)=2.63, p>.05\right.$ and $F_{2}<1$ for response latencies, and $F_{1}(1,47)=1.78, p>.05$ and $F_{2}<1$, for error rates].

In order to assess the possibility that orthographic effects may be extremely short in nature, additional analyses were conducted for primes and targets that were presented in immediate succession (i.e., a lag of 0 ). However, the results mirrored the overall repetition priming results in that the identical priming effect $(66 \mathrm{msec})$ was significant $\left[F_{2}(1,3)=10.71, p<.05\right]$ whereas the reversed priming effect $(18 \mathrm{msec})$ was not $\left(F_{2}<1\right)$.

Nonword results. Analyses showed that identical primes (e.g., the first occurrence of DUT in the DUT-DUT pair) and reversed primes (e.g., the occurrence of TUD in the TUD-DUT pair) did not differ significantly from each other $(778 \mathrm{msec}$ for identical primes and $777 \mathrm{msec}$ for reversed primes; $F_{1}<1$ and $F_{2}<1$ ). Likewise, targets primed by identical repetitions $(760 \mathrm{msec}$ for the second occurrence of DUT in the DUT-DUT pair) were not significantly faster than targets primed by reversed repetitions [ $776 \mathrm{msec}$ for the occurrence of DUT in the TUD-DUT pair; $F_{1}(1,47)=1.89, p>.05$ and $\left.F_{2}<1\right]$. The analysis did not reveal a significant interaction between primes and targets on response latencies $\left[F_{1}(1,47)=1.03, p>.05\right.$ and $\left.F_{2}<1\right]$.
Since DUT- and TUD-type primes did not differ significantly, they were combined to simplify further analyses ( $M=778 \mathrm{msec})$. In the assessment of specific repetition priming effects (see Table 4), planned comparisons showed that targets (e.g., DUT) were not significantly facilitated by identical primes [e.g., DUT; $F_{1}(1,47)=3.22, p>.05$ and $F_{2}<1$ ] or by reversed primes (e.g., TUD; $F_{1}<1$ and $\mathrm{F} 2<1)$. With respect to the error rate data, no significant effects were noted.

As for the word results, additional analyses were conducted to determine whether primes and targets presented in immediate succession would exhibit repetition priming effects. However, neither the identical priming effect $\left(F_{2}<\right.$ $1)$ nor the reversed priming effect $\left(F_{2}<1\right)$ was significant.

\section{Discussion}

The short-term repetition priming results of Experiment 2 mirrored the long-term repetition priming results of Experiment 1. In both experiments, significant repetition priming effects were observed for identical word primes (i.e., DOG-DOG). However, significant repetition priming effects were not observed for reversed word primes (e.g., GOD-DOG), identical nonword primes (e.g., DUT-DUT), or reversed nonword primes (e.g., TUD-DUT). Additionally, a significant repetition priming effect on error rates for identical word primes, which missed significance in Experiment 1, was achieved in Experiment 2.

\section{EXPERIMENT 3}

Besides the temporal succession of the prime and target, repetition priming effects have also been found to be sensitive to stimulus degradation. Stimulus degradation results in processing costs such as increased response latencies and higher error rates in reaction time tasks (see Jordan \& Huntsman, 1995; Sternberg, 1969; Van Orden, 1987). In addition, across a wide variety of tasks, stimulus degradation has been found to enhance repetition priming effects (Becker \& Killion, 1977; Kirsner \& Dunn, 1985; Kirsner et al., 1987; Massaro, Jones, Lipscomb, \& Scholz, 1978; Meyer, Schvaneveldt, \& Ruddy, 1975; Scarborough et al., 1977). Researchers who have examined lexical access under conditions of stimulus degradation have done so through various alterations of the stimulus. Typical degradation techniques include pattern masking (Scarborough et al., 1977), brief-exposure pattern masking (Van Orden, 1987), progressive demasking (Grainger \& Segui, 1990), progressive degfragmentation (Snodgrass \& Mintzer, 1993), and spatial misorientation (Howard, 1991; Jordan \& Huntsman, 1990, 1995; Kolers, 1968; Koriat \& Norman, 1984, 1985, 1989; Masson, 1986; Navon, 1978).

Experiment 3 accomplished stimulus degradation through spatial misorientation. Misorientation has been found to be detrimental to the processing times of text (Kolers, 1968; Masson, 1986) as well as individual words (Jordan \& Huntsman, 1990, 1995; Koriat \& Norman, 1985, 1989; Navon, 1978). Furthermore, misorientation 
effects have been found to be more detrimental for longer words than for shorter words (Jordan \& Huntsman, 1995; Koriat \& Norman, 1985, 1989). These word-length effects, which are apparent under conditions of misorientation but not observed under normal viewing conditions (i.e., upright), suggest that in attempts to recover spatial order information, misorientation induces a shift from parallel processing of letters to serial, letter-by-letter processing (see Howard, 1991; Jordan \& Huntsman, 1995; Koriat \& Norman, 1985). The retarded response latencies caused by misorientation, which increase as a function of word length, suggest the use of a disconnectionist, slower, sequential letter-by-letter identification procedure. Interestingly, the experimentally induced letter-by-letter reading in normal adults parallels the letter-by-letter reading demonstrated by brain-damaged patients (see Friedman \& Hadley, 1992; Koriat \& Norman, 1985; Marshall $\&$ Newcombe, 1980).

If misorientation induces letter-by-letter processing and also enhances the repetition priming effect, using a short-term priming task coupled with stimulus misorientation may provide the optimal conditions under which the GOD-DOG priming effect occurs. The orientation chosen was $180^{\circ}$ from the normal upright orientation. The logic behind the upside-down presentation mode flows from the direction in which the English writing system is read. Since English is read from left to right, and misorientation induces letter-by-letter processing, it is possible that the upside-down word GOD may be initially processed as the upside-down letters D, O, and G prior to rotation. Therefore, Experiment 3 was designed to encourage the negligible repetition priming effects found for reversed repetitions in Experiments 1 and 2 to become more substantial. In addition, the repetition priming effect for nonwords has been found to be enhanced through stimulus degradation (see Kirsner \& Dunn, 1985). Therefore, it was reasoned that although insignificant repetition priming effects for nonwords were observed in both identical (e.g., DUT did not prime DUT) and reversed (e.g., TUD did not prime DUT) prime-target conditions of EXperiments 1 and 2, significant repetition priming effects for nonwords might be observed in Experiment 3.

\section{Method}

Participants. Forty-eight different individuals from the same population as that used in the previous experiments participated in Experiment 3.

Procedure and Design. Besides a change in the viewing condition, the method in Experiment 3 was identical to that used in Experiment 2 .

Viewing condition. Stimulus degradation was accomplished by presenting all of the words and nonwords used in Experiment 3 rotated $180^{\circ}$ relative to the normal upright orientation used in Experiments 1 and 2. The viewing distance and upside-down orientation were maintained by a headrest and a chinrest.

Scoring of data. Since misorientation results in an increase in response latencies, the mean cutoff for participants was increased by $500 \mathrm{msec}$. Therefore, if the lexical decision response latencies for a participant yielded a grand mean greater than $1.500 \mathrm{msec}$, that par-
Table 5

Experiment 3 Prime and Target Examples, Mean Lexical Decision Response Times (in Milliseconds), Error Rates (in Percentages), and Repetition Priming Effects for Words

\begin{tabular}{lccc} 
& $\begin{array}{c}\text { Control } \\
\text { Prime Example }\end{array}$ & $\begin{array}{c}\text { Target Primed by } \\
\text { Identical Word }\end{array}$ & $\begin{array}{c}\text { Target Primed by } \\
\text { Reversed Word }\end{array}$ \\
\hline Prime & DOG & DOG & GOD \\
Target & & DOG & DOG \\
Response times & 1,198 & 1,012 & 1,209 \\
Priming effect & & $186^{*}$ & -11 \\
Error rates & 10.58 & 4.06 & 9.57 \\
Priming effect & & 6.52 & 1.01 \\
\hline
\end{tabular}

* Significant repetition priming effect.

Table 6

Experiment 3 Prime and Target Examples, Mean Lexical

Decision Response Times (in Milliseconds), Error Rates (in Percentages), and Repetition Priming Effects for Nonwords

Control Target Primed by Target Primed by Prime Example Identical Nonword Reversed Nonword

\begin{tabular}{lccr}
\hline Prime & DUT & DUT & TUD \\
Target & & DUT & DUT \\
Response times & 1,397 & 1,207 & 1,396 \\
Priming effect & & $190^{*}$ & 1 \\
Error rates & 6.21 & 3.81 & 6.75 \\
Priming effect & & 2.40 & -.54 \\
\hline
\end{tabular}

*Significant repetition priming effect.

ticipant's data were eliminated from all analyses. Besides this change, the scoring of the data was the same as that of Experiments 1 and 2.

\section{Results}

Prime and target examples, mean lexical decision response times (in milliseconds), PE, and repetition priming effects for words and nonwords are presented in Tables 5 and 6 , respectively.

Word results. Analyses indicated that identical primes (e.g., the first occurrence of DOG in the DOG-DOG pair) and reversed primes (e.g., the occurrence of GOD in the GOD-DOG pair) did not differ significantly from each other [1,198 msec and $10.58 \mathrm{PE}$ for identical primes and $1,198 \mathrm{msec}$ and $10.59 \mathrm{PE}$ for reversed primes; $F_{1}<1$ and $F_{2}<1$ for response latencies, and $F_{1}<1$ and $F_{2}(1,17)=$ $2.90, p>.05$ for error rates]. However, targets primed by identical repetitions $(1,012 \mathrm{msec}$ and $4.06 \mathrm{PE}$ for the second occurrence of DOG in the DOG-DOG pair) were significantly faster and less error prone than targets primed by reversed repetitions $[1,209 \mathrm{msec}$ and $9.57 \mathrm{PE}$ for the occurrence of DOG in the GOD-DOG pair; $F_{1}(1,47)=49.13$, $p<.001$ and $F_{2}(1,17)=9.71, p<.01$ for response latencies, and $F_{1}(1,47)=28.06, p<.001$ and $F_{2}(1,17)=$ $8.61, p<.01$ for error rates]. Furthermore, analyses revealed a significant interaction between primes and targets on response latencies $\left[F_{1}(1,47)=20.96, p<.001\right.$ and $\left.F_{2}(1,17)=8.62, p<.01\right]$ and error rates $\left[F_{1}(1,47)=\right.$ $16.02, p<.001$ and $\left.F_{2}(1,17)=6.36, p<.05\right]$.

Since DOG- and GOD-type primes did not differ significantly, they were combined to simplify further analyses ( $M=1,198 \mathrm{msec}$ and 10.58 PE). In the assessment of 
specific repetition priming effects (see Table 5), planned comparisons showed that targets (e.g., DOG) were facilitated by identical primes (e.g., DOG) but not by reversed primes (e.g., GOD). The identical priming effect ( $186 \mathrm{msec}$ and 6.52 PE) was statistically significant for response latencies $\left[F_{1}(1,47)=60.73, p<.001\right.$ and $F_{2}(1,17)=26.92$, $p<.001]$ and error rates $\left[F_{1}(1,47)=82.08, p<.001\right.$ and $\left.F_{2}(1,17)=6.98, p<.05\right]$. Targets were not significantly facilitated $(-11 \mathrm{msec}$ and $1.01 \mathrm{PE})$ by reversed primes $\left[F_{1}<1\right.$ and $F_{2}<1$ for response latencies and $F_{1}(1,47)=$ $2.08, p>.05$ and $F_{2}<1$ for error rates].

As in Experiment 2, additional analyses were conducted for sequentially presented primes and targets. As expected, the identical priming effect $(190 \mathrm{msec})$ was significant $\left[F_{2}(1,3)=29.82, p<.05\right]$, but the reversed priming effect $(-6 \mathrm{msec})$ was not $\left(F_{2}<1\right)$.

Nonword results. Analyses showed that identical primes (e.g., the first occurrence of DUT in the DUT-DUT pair) and reversed primes (e.g., the occurrence of TUD in the TUD-DUT pair) did not differ significantly from each other $(1,397 \mathrm{msec}$ and 4.75 PE for identical primes and $1,396 \mathrm{msec}$ and $7.67 \mathrm{PE}$ for reversed primes; $F_{1}<1$ and $F_{2}<1$ for response latencies $F_{1}<1$ and $F_{2}<1$ for error rates). However, targets primed by identical repetitions $(1,207 \mathrm{msec}$ and 3.81 PE for the second occurrence of DUT in the DUT-DUT pair) were significantly faster and less error prone than targets primed by reversed repetitions $[1,396 \mathrm{msec}$ and $6.75 \mathrm{PE}$ for the occurrence of DUT in the TUD-DUT pair; $F_{1}(1,47)=28.15, p<.001$ and $F_{2}(1,17)=$ $8.22, p<.05$ for response latencies, and $F_{1}(1,47)=4.48$, $p<.05$ and $F_{2}(1,17)=4.69, p<.05$ for error rates] Analyses also revealed a significant interaction between primes and targets on response latencies $\left[F_{1}(1,47)=\right.$ $28.10, p<.001$ and $\left.F_{2}(1,17)=6.28, p<.05\right]$ and error rates $\left[F_{1}(1,47)=15.73, p<.001\right.$ and $\left.F_{2}(1,17)=5.79, p<.05\right]$.

Since DUT- and TUD-type primes did not differ significantly, they were combined to simplify further analyses ( $M=1,397 \mathrm{msec}$ and 6.21 PE). In the assessment of specific repetition priming effects (see Table 6), planned comparisons showed that targets (e.g., DUT) were facilitated by identical primes (e.g., DUT) but not by reversed primes (e.g., TUD). The identical priming effect (190 msec and $2.40 \mathrm{PE}$ ) was statistically significant for response latencies $\left[F_{1}(1,47)=41.88, p<.001\right.$ and $F_{2}(1,17)=$ $92.13, p<.001]$ and error rates $\left[F_{1}(1,47)=13.47, p<\right.$ .001 and $\left.F_{2}(1,17)=11.20, p<.01\right]$. Response latencies to targets were not significantly facilitated $(1 \mathrm{msec}$ and $-.54 \mathrm{PE})$ by reversed primes $\left(F_{1}<1\right.$ and $F_{2}<1$ for response latencies and $F_{1}<1$ and $F_{2}<1$ for error rates).

Once again, additional analyses were conducted for targets that immediately followed primes. The results mirrored the overall repetition priming results in that the identical priming effect $(193 \mathrm{msec})$ was significant $\left[F_{2}(1,3)=\right.$ $28.34, p<.05]$, but the reversed priming effect $(3 \mathrm{msec})$ was not $\left(F_{2}<1\right)$.

\section{Discussion}

As expected, with the use of stimulus degradation, the identical repetition priming effect that was found for words (e.g., DOG-DOG) in Experiments 1 and 2 was magnified in Experiment 3. In addition, Experiment 3 produced a significant identical repetition priming effect for the nonwords (e.g., TUD-TUD) that was not observed in the previous experiments. Since nonwords cannot share a morphological relationship with other nonwords, the identical priming effect observed for the nonwords in Experiment 3 provides partial support for the directaccess model. However, this orthographic effect is not distinguishable from phonological activation since identical nonwords share a phonological relationship (e.g., TUD sounds like TUD).

Full support for direct access was lacking because, like Experiments 1 and 2, Experiment 3 did not produce significant priming effects for the reversed words (i.e., GODDOG) or reversed nonwords (i.e., TUD-DUT). Previous research (Howard, 1991; Jordan \& Huntsman, 1995; Koriat \& Norman, 1985, 1989) has suggested that misorientation induces letter-by-letter processing. The repetition priming effect observed for identical words and nonwords but not reversed words and nonwords suggests that this induced letter-by-letter processing is position sensitive. For example, the letters $D, O$, and $G$ will serve as a prime if they are repeated in the same sequence (i.e., DOG) but not if they are repeated in reversed sequence (i.e., GOD).

\section{GENERAL DISCUSSION}

There were three principal findings in the present project. First, a null repetition priming effect was observed in all three experiments for stimulus items that shared letter identity but not letter position. Second, a repetition priming effect for words was observed in all three experiments for stimulus items that shared letter identity as well as letter position. This finding indicates that facilitation arises when order as well as letter identity are preserved over repetition. Finally, under conditions of stimulus misorientation, a repetition priming effect was observed for nonwords that shared order and letter identity but not for nonwords that shared letter identity but did not share order identity.

The finding that the presentation of a word will facilitate later identification of morphologically and phonologically related but not exclusively orthographically related words supports the work of other researchers (see Feldman \& Moskovljevic, 1987; Fowler et al., 1985; Hanson \& Wilkenfeld, 1985; Kirsner et al., 1987; Lima, 1987; Murrell \& Morton, 1974; Stanners, Neiser, Hernon, \& Hall, 1979; Stanners, Neiser, \& Painton, 1979). Directaccess theorists (e.g., Aaronson \& Ferres, 1983; Baron, 1973; Becker, 1976, 1980; Bower, 1970; Forster \& Chambers, 1973; Frederiksen \& Kroll, 1976; Goodman, 1969; Green \& Shallice, 1976; Huey, 1908; Kolers, 1970; Martin \& Jensen, 1988; Paap et al., 1982; Smith, 1971) would find it difficult to dismiss the present observations without acknowledging the role morphology and phonology obviously play in word recognition.

Although the null GOD-DOG priming effect is evidence against direct access, it is important to view the inter- 
pretations of null results with caution. To overinterpret null results to indicate the absence of a process leads to a dangerous game of science (see related discussions in Bauer \& Stanovich, 1980; Besner et al., 1981; Carello et al., 1992; Glushko, 1981; Lukatela et al., 1993; McCusker et al., 1981; Van Orden, 1987; Van Orden et al., 1990). Although the prior use of this logic has been used by direct-access theorists to dismiss phonology (e.g., Aaronson \& Ferres, 1983; Baron, 1973; Becker, 1976, 1980; Bower, 1970; Forster \& Chambers, 1973; Frederiksen \& Kroll, 1976; Goodman, 1969; Green \& Shallice, 1976; Kolers, 1970; Martin \& Jensen, 1988; Paap et al., 1982; Smith, 1971). Nevertheless, the conservative researcher would be advised to regard the present data as a way of providing constraints on future specifications of how orthographic information is used. It is hoped that the failure of this study to provide explicit evidence for direct visual access that is distinguishable from other processes will encourage the shifting away from theories that postulate independent mechanisms of lexical access (e.g., Coltheart, 1978, 1980, 1985; Coltheart et al., 1977; Davelaar et al., 1978; Meyer \& Ruddy, 1973; Norris \& Brown, 1985; Seidenberg, 1985; Seidenberg et al., 1984; Stanovich \& Bauer, 1978; Waters et al., 1984). It is hoped that the present effort will motivate further development of theories in which multiple and varied levels of lexical representations or substructures are activated through a common matrix of connection weights (see Carello et al., 1992; Carr \& Pollatsek, 1985; Lukatela et al., 1993; Van Orden, 1987; Van Orden et al., 1990). In this way, the orthographic representation of a word will activate various levels of lexical representations (i.e., phonological, morphological, semantic, and syntactic) that covary with the word's orthographic features. This set of active lexical representations, the subset of linguistic features that are typically used for most occurrences of the word, results in word recognition. As elucidated by Van Orden's phonological coherence hypothesis, the covariation between orthographic and phonological representations is more closely linked than the covariation between orthographic representations and other linguistic structures (e.g., morphological, semantic, and syntactic).

In a field where researchers would be naive not to assume that orthographic information plays a role in visual word recognition, specifying the manner in which orthographic information is used is not so simple. Therefore, despite null results of the present effort, there are numerous studies that demonstrate that orthographic information does play a role in word recognition. For instance, studies on initial letter sequences shared by other words (Lima \& Inhoff, 1985) and the orthographic neighborhood structure of words (see Andrews, 1989, 1992; Coltheart et al., 1977; Grainger, 1990; Grainger, O'Regan, Jacobs, \& Segui, 1989, 1992; Grainger \& Segui, 1990; Huntsman \& Lima, 1996) have been useful in defining the terms and parameters of models of word recognition such as the serial-search model (Forster,
1976, 1989; Rubenstein, Garfield, \& Millikan, 1970), activation-verification models (Becker, 1976, 1980; Paap, McDonald, Schvaneveldt, \& Noel, 1987; Paap et al., 1982), the interactive-activation model (McClelland \& Rumelhart, 1981; Rumelhart \& McClelland, 1982), and the parallel-distributed-processing model (Seidenberg \& McClelland, 1989).

In conclusion, many experiments have affirmed the influence that morphological codes have on word recognition. For instance, HEALTH primes HEAL (Fowler et al., 1985), UNAWARE primes aWARE (Stanners, Neiser, \& Painton, 1979), WALKING primes WALK (Stanners, Neiser, \& Painton, 1979), and DISHONEST primes HONEST (Lima, 1987). Likewise, many experiments have also affirmed the influence that phonological codes have on word recognition. For example, BRIBE primes TRIBE (Meyer et al., 1974), EIGHT primes MATE (Hillinger, 1980), TAYBLE primes CHAIR (Lukatela \& Turvey, 1991), and TOWED primes FROG (Lukatela et al., 1993). However, few experiments have provided affirmation for the influence that orthographic codes have on word recognition irrespective of morphological or phonological codes. The present experiment endeavored to fill this void by providing a test of the direct-access model. When put to the test, the direct-access model did not prevail because GOD did not prime DOG. It would seem that while a Rows is still a ROSE (Van Orden, 1987), GOD is not a DOG.

\section{REFERENCES}

Aaronson, D., \& Ferres, S. (1983). A model for coding lexical categories during reading. Journal of Experimental Psychology: Human Perception \& Performance, 9, 700-725.

ANDREWS, S. (1989). Frequency and neighborhood effects on lexical access: Activation or search? Journal of Experimental Psychology: Learning, Memory, \& Cognition, 15, 802-814.

ANDREwS, S. (1992). Frequency and neighborhood effects on lexical access: Lexical similarity or orthographic redundancy? Journal of Experimental Psychology: Learning, Memory, \& Cognition, 18, 234-254.

Baron, J. (1973). Phonemic stage not necessary for reading. Quarterly Journal of Experimental Psychology, 25, 241-246.

Bauer, D. W., \& Stanovich, K. E. (1980). Lexical access and the spelling-to-sound regularity effect. Memory \& Cognition, 8, 424-432.

BECKER, C. A. (1976). Allocation of attention during visual word recognition. Journal of Experimental Psychology: Human Perception \& Performance, 2, 556-566.

BECKER, C. A. (1980). Semantic context effects in visual word recognition: An analysis of semantic strategies. Memory \& Cognition, $\mathbf{8}$, 493-512.

BECKER, C. A., \& Killion, T. H. (1977). Interaction of visual and cognitive effects in word recognition. Journal of Experimental Psychology: Human Perception \& Performance, 3, 389-401

Besner, D., Davies, J., \& Daniels, S. (1981), Reading for meaning: The effects of concurrent articulation. Quarterly Joumal of Experimental Psychology, 33A, 415-437

BloOMField, L. (1942). Linguistics and reading. Elementary English. 19, $125-130$

Bower, T. G. R. (1970). Reading by eye. In H. Levin \& J. P. Williams (Eds.), Basic studies on reading (pp. 134-146). New York: Basic Books.

Bradshaw, J. L., \& Nettleton, N. C. (1974). Articulatory interference and the mown-down heterophone effect. .ournal of Experimental Psichology, 102, 88-94.

Carello, C.. Turvey, M. T., \& Lukatel.a, G. (1992). Can theories of 
word recognition remain stubbornly nonphonological? In R. Frost \& L. Katz (Eds.), Orthography, phonology, morphology, and meaning (pp. 211-226). Amsterdam: Elsevier.

Carr, T. H., \& Pollatsek, A. (1985). Recognizing printed words: A look at current models. In D. Besner, T. G. Waller, \& G. E. MacKinnon (Eds.), Reading research (Vol. 5, pp. 1-82). Orlando, FL: Academic Press.

ColThearT, M. (1978). Lexical access in simple reading tasks. In G. Underwood (Ed.), Strategies of information processing (pp. 151-216). New York: Academic Press.

Coltheart, M. (1980). Reading, phonological recoding, and deep dyslexia. In M. Coltheart, K. Patterson, \& J. C. Marshall (Eds.), Deep dyslexia (pp. 197-226). London: Routledge \& Kegan Paul.

Coltheart, M. (1985). In defense of dual-route models of reading. Behavioral \& Brain Sciences, 8, 709-710.

Coltheart, M., Davelaar, E., Jonasson, J. T., \& Besner, D. (1977). Access to the internal lexicon. In S. Dornic (Ed.), Attention and performance VI (pp. 535-555). Hillsdale, NJ: Erlbaum.

Corcoran, D. W. J. (1966). An acoustic factor in letter cancellation. Nature, $210,658$.

Davelaar, E., Coltheart, M., Besner, D., \& Jonasson, J. T. (1978). Phonological recoding and lexical access. Memory \& Cognition, 6, 391-402.

Feldman, L. B., \& Moskovluevic, J. (1987). Repetition priming is not purely episodic in origin. Journal of Experimental Psychology: Learning, Memory, \& Cognition, 13, 573-581.

FLEMING, K. K. (1993). Phonologically mediated priming in spoken and printed word recognition. Journal of Experimental Psychology: Learning, Memory, \& Cognition, 19, 272-284.

Forbach, G. B., StanNers, R. F., \& Hochhaus, L. (1974). Repetition and practice effects in a lexical decision task. Memory \& Cognition, 2, 337.339.

FORSTER, K. I. (1976). Accessing the mental lexicon. In R. J. Wales \& E. Walker (Eds.), New approaches to language mechanisms (pp. 257287). Amsterdam: North-Holland.

FORSTER, K. I. (1989). Basic issues in lexical processing. In W. MarslenWilson (Ed.), Lexical representation and process (pp. 75-107). Cambridge, MA: MIT Press.

Forster, K. I., \& ChAmbers, S. M. (1973). Lexical access and naming time. Journal of Verbal Learning \& Verbal Behavior, 12, 627-635.

Fowler, C. A., NAPPS, S. E., \& FELDMAN, L. (1985). Relations among regular and irregular morphologically related words in the lexicon as revealed by repetition priming. Memory \& Cognition, 13, 241-255.

Frederiksen, J. R., \& Kroll, J. F. (1976). Spelling and sound: Approaches to the internal lexicon. Journal of Experimental Psychology: Human Perception \& Performance, 2, 363-379.

FrICK, R. W. (1995). Accepting the null hypothesis. Memory \& Cognition, 23, 132-138.

Friedman, R. B. (1995). Two types of phonological alexia. Cortex, 31, 397-403.

Friedman, R. B., \& HADLEY, J. A. (1992). Letter by letter surface alexia. Cognitive Neuropsychology, 9, 185-208.

Gibson, E. (1970). The ontogeny of reading. American Psychologist, 25, 136-143.

GlushKo, R. (1981). Principles for pronouncing print: The psychology of phonology. In A. M. Lesgold \& C. A. Perfetti (Eds.), Interactive processes in reading (pp. 61-84). Hillsdale, NJ: Erlbaum.

Goodman, K. S. (1969). Analysis of reading miscues: Applied psycholinguistics. Reading Research Quarterly, 5, 9-30.

Gough, P. B. (1972). One second of reading. In J. K. Kavanaugh \& I. G. Mattingly (Eds.), Language by ear and by eve (pp. 331-358). Cambridge, MA: MIT Press.

GRAINGER, J. (1990). Word frequency and neighborhood frequency effects in lexical decision and naming. Journal of Memory \& Language, 29, 228-244.

Grainger, J., O'Regan, J. K., Jacobs, A. M., \& Segui, J. (1989). On the role of competing word units in visual word recognition: The neighborhood frequency effect. Perception \& Psichophysics, 45, 189-195.

Grainger, J., O'Regan, J. K., Jacobs, A. M., \& Segui, J. (1992). Neighborhood frequency effects and letter visibility in visual word recognition. Perception \& Psichophisics, 51, 49-56.
Grainger, J., \& Segui, J. (1990). Neighborhood frequency effects in visual word recognition: A comparison of lexical decision and masked identification latencies. Perception \& Psychophysics, 47, 191-198.

Green, D. W., \& Shallice, T. (1976). Direct visual access in reading for meaning. Memory \& Cognition, 4, 753-758.

GrossberG, S., \& StONE, G. (1986). Neural dynamics of word recognition and recall: Priming, learning, and resonance. Psychological Review, 93, 46-74.

Hansen, D., \& Rodgers, T. S. (1968). An exploration of psycholinguistic units in initial reading. In K. S. Goodman (Ed.), The psycholinguistic nature of the reading process ( $\mathrm{pp}$. 42-86). Detroit: Wayne State University Press.

Hanson, V. L., \& Wilkenfeld, D. (1985). Morphology and lexical organization in deaf readers. Language \& Speech, 28, 269-279.

HillingER, M. L. (1980). Priming effects with phonemically similar words: The encoding-bias hypothesis reconsidered. Memory \& Cognition, 8, 115-123.

Howard, D. (1991). Letter-by-letter readers: Evidence for parallel processing. In D. Besner \& G. W. Humphreys (Eds.), Basic processes in reading: Visual word recognition (pp. 34-76). Hillsdale, $\mathrm{NJ}$ : Erlbaum.

HueY, E. B. (1908). The psychology and pedagogy of reading. Cambridge, MA: MIT Press.

Humphreys, G. W., EvetT, L. J., \& TAylor, D. E. (1982). Automatic phonological priming in visual word recognition. Memory \& Cognition, 10, 576-590.

Huntsman, L. A., \& Lima, S. D. (1996). Orthographic neighborhood structure and lexical access. Journal of Psycholinguistic Research, 25, 413-425.

Huston, A. M. (1992). Visual dyslexia. In A. M. Huston (Ed.), Understanding dyslexia: A practical approach for parents and teachers (pp. 47-65). Lanham, MD: Madison Books.

INHOFF, A. W., \& TOPOLSKI, R. (1994). Use of phonological codes during eye fixations and in on-line delayed naming tasks. Journal of Memory \& Language, 33, 689-713.

JARED, D., \& SEIDENBERG, M. S. (1991). Does word identification proceed from spelling to sound to meaning? Journal of Experimental Psychology: General, 120, 358-394.

Jordan, K., \& HunTSMAN, L. A. (1990). Image rotation of misoriented letter strings: Effects of orientation cuing and repetition. Perception \& Psychophysics, 48, 363-374.

Jordan, K., \& HUNTSMAN, L. A. (1995). Repetition of misoriented words reduces lexical-decision response times at repeated and novel orientations. Journal of Experimental Psychology: Human Perception \& Performance, 21, 963-977.

KirSNER, K., \& DunN, J. C. (1985). The perceptual record: A common factor in repetition priming and attribute retention. In M. I. Posner \& O. S. M. Marin (Eds.), Attention and performance XI (pp. 113-131). Hillsdale, NJ: Erlbaum.

KirSner, K., DunN, J. C., \& Standen, P. (1987). Record-based word recognition. In M. Coltheart (Ed.), Attention and performance XII: The psychology of reading (pp. 147-167). Hillsdale, NJ: Erlbaum.

KOLERS, P. A. (1968). The recognition of geometrically transformed text. Perception \& Psychophysics, 3, 57-64.

KolERs, P. A. (1970). Three stages of reading. In H. Levin \& J. P. Williams (Eds.), Basic studies on reading (pp. 90-118). New York: Basic Books.

KORIAT, A., \& NORMAN, J. (1984). What is rotated in mental rotation? Journal of Experimental Psychology: Learning, Memory, \& Cognition, 10, 421-434.

Koriat, A., \& Norman, J. (1985). Reading rotated words. Journal of Experimental Psychology: Human Perception \& Performance, 11, 490-508.

Koriat, A., \& Norman, J. (1989). Why is word recognition impaired by disorientation while the identification of single letters is not? Journal of Experimental Psychology: Human Perception \& Performance, 15, 153-163.

KuČERA, H., \& Francis, W. N. (1967). Computational analysis of present-day American English. Providence, RI: Brown University Press.

Lesch, M. F., \& Pollatsek, A. (1993). Automatic access of semantic information by phonological codes in visual word recognition. Journal of Experimental Psychology: Learning, Memory, \& Cognition, 19. 285-294. 
Lima, S. D. (1987, May). Stem representation for prefixed words: Effects of compositionality of meaning. Paper presented at the annual meeting of the Midwestern Psychological Association, Chicago.

LIMA, S. D., \& INHOFF, A. W. (1985). Lexical access during eye fixations in reading: Effects of word-initial letter sequence. Journal of Experimental Psychology: Human Perception \& Performance, 11, 272-285.

Lukatela, G., Lukatela, K., \& Turvey, M. T. (1993). Further evidence for phonological constraints on visual lexical access: TOWED primes FROG. Perception \& Psychophysics, 53, 461-466.

Lukatela, G., \& Turvey, M. T. (1991). Phonological access of the lexicon: Evidence from associative priming with pseudohomophones. Journal of Experimental Psychology: Human Perception \& Performance, 17, 951-966.

Lukatela, G., \& Turvey, M. T. (1993). Similar attentional, frequency, and associative effects for pseudohomophones and words. Journal of Experimental Psychology: Human Perception \& Performance, 19, 166-178.

Lukatela, G., \& Turvey, M. T. (1994a). Visual lexical access is initially phonological: 1 . Evidence from associative priming by words, homophones, and pseudohomophones. Journal of Experimental Psychology: General, 123, 107-128.

Lukatela, G., \& Turvey, M. T. (1994b). Visual lexical access is initially phonological: 2 . Evidence from associative priming by homophones, and pseudohomophones. Journal of Experimental Psychology: General, 123, 331-353.

Marshall, J. C., \& Newcombe, F. (1973). Patterns of paralexia: A psycholinguistic approach. Journal of Psycholinguistic Research, 2, 175-199.

Marshall, J. C., \& Newcombe, F. (1980). The conceptual status of deep dyslexia: An historical perspective. In M. Coltheart, K. Patterson, \& J. C. Marshall (Eds.), Deep dyslexia (pp. 1-21). London: Routledge \& Kegan Paul.

Martin, R. C., \& Jensen, C. R. (1988). Phonological priming in the lexical decision task: A failure to replicate. Memory \& Cognition, 16, 505-521.

Massaro, D. W., Jones, R. D., Lipscomb, D., \& Scholz, R. (1978). Role or prior knowledge on naming and lexical decisions with good and poor stimulus information. Journal of Experimental Psychology: Human Learning \& Memory, 4, 498-512.

MAsson, M. E. J. (1986). Identification of typographically transformed words: Instance-based skill acquisition. Journal of Experimental Psychology: Learning, Memory, \& Cognition, 12, 479.488.

Masson, M. E. J., \& Freedman, L. (1990). Fluent identification of repeated words. Journal of Experimental Psychology: Learning, Memory, \& Cognition, 16, 355-373.

MCClelland, J. L., \& RumelhaRT, D. E. (1981). An interactive activation model of context effects in letter perception: Part 1. An account of basic findings. Psychological Review, 88, 375-407.

McCusker, L. X., Hillinger, M. L., \& Bias, R. G. (1981). Phonological recoding and reading. Psychological Bulletin, 89, 217-245.

MEYER, D. E., \& RUDDY, M. G. (1973, November). Lexical-memory retrieval bases on graphemic and phonemic representation of printed words. Paper presented at the annual meeting of the Psychonomic Society, St. Louis.

Meyer, D. E., Schvaneveldt, R. W., \& Ruddy, M. G. (1974). Functions of graphemic and phonemic codes in visual word-recognition. Memory \& Cognition, 2, 309-321.

Meyer, D. E., Schvaneveldt, R. W., \& Ruddy, M. G. (1975). Loci of contextual effects on visual word recognition. In P. M. A. Rabbitt \& S. Dornic (Eds.), Attention and performance V (pp. 1-27). New York: Academic Press.

Monsell, S. (1985). Repetition and the lexicon. In A. W. Ellis (Ed.), Progress in the psychology of language (Vol. 1, pp. 147-195). Hillsdale, NJ: Erlbaum.

MONSELL, S. (1987). Non-visual orthographic processing and the orthographic lexicon. In M. Coltheart (Ed.), Attention and performance XII: The psychology of reading (pp. 36-55). Hillsdale, NJ: Erlbaum.

Morton, J. (1979). Facilitation in word recognition: Experiments causing change in the logogen models. In P. A. Kolers, M. E. Wrolsstad, \& H. Bouma (Eds.), Processing of visible language (Vol. I, pp. 259268). New York: Plenum.
Murrell., G. A., \& Morton, J. (1974). Word recognition and morphemic structure. Journal of Experimental Psychology, 102, 963-968.

NAPPS, S. (1985). Morphological, semantic, and formal relations among words and the organization of the mental lexicon. Unpublished doctoral dissertation, Dartmouth College.

NAPPS, S., \& FowLER, C. A. (1987). The effect of orthography on the organization of the mental lexicon. Journal of Psycholinguistic Research, 16, 252-257.

Navon, D. (1978). Perception of misoriented words and letter strings. Canadian Journal of Psychology, 32, 129-140.

Norris, D., \& BRown, G. (1985). Race models and analogy theories: A dead heat? Cognition, 20, 155-168.

Orton, S. T. (1925). Word-blindness in school children. Archives of Neurology \& Psychiatry, 14, 581-615.

PaAp, K. R., McDonald, J. E., Schvaneveldt, R. W., \& Noel, R. W. (1987). Frequency and pronounceability in visually presented naming and lexical decision tasks. In M. Coltheart (Ed.), Attention and performance XII: The psychology of reading (pp. 115-134). Hillsdale, $\mathrm{NJ}$ : Erlbaum.

PaAP, K. R., Newsome, S. L., McDonald, J. E., \& SchVaneveldt, R. W. (1982). An activation-verification model for letter and word recognition: The word-superiority effect. Psychological Review, 89, 573-594.

RATCLIFF, R., HoCKLEY, W., \& MCKoON, G. (1985). Components of activation: Repetition and priming effects in lexical decision and recognition. Journal of Experimental Psychology: General, 114, 435-450.

Rubenstein, H., Garfield, L., \& Millikan, J. A. (1970). Homographic entries in the internal lexicon. Journal of Verbal Learning \& Verbal Behavior, 9, 487-494.

Rubenstein, H., Lewis, S. S., \& Rubenstein, M. A. (1971). Evidence for phonemic recoding in visual word recognition. Journal of Verbal Learning \& Verbal Behavior, 10, 645-657.

Rumelhart, D. E., \& McClelland, J. L. (1982). An interactive activation model of context effects in letter perception: Pt. 2. The contextual enhancement effect and some tests and extensions of the model. Psychological Review, 89, 60-94.

Scarborough, D. L., Cortese, C., \& Scarborough, H. S. (1977). Frequency and repetition effects in lexical memory. Journal of Experimental Psychology: Human Perception \& Performance, 3, 1-17.

SCarborough, D. L., Gerard, L., \& CorTese, C. (1984). Independence of lexical access in bilingual word recognition. Journal of Verbal Learning \& Verbal Behavior, 23, 84-89.

Seidenberg, M. S. (1985). The time course of phonological code activation in two writing systems. Cognition, 19, 1-30.

SEIDENBERG, M. S. (1992). Beyond orthographic depth of reading: Equitable division of labor. In R. Frost \& L. Katz (Eds.), Orthography, phonology, morphology, and meaning (pp. 85-118). Amsterdam North-Holland.

Seidengerg, M. S., \& MCClelland, J. L. (1989). A distributed developmental model of word recognition and naming. Psychological Review, 96, 523-568.

SeidenberG, M. S., Waters, G. S., Barnes, M., \& Tanenhaus, M. K (1984). When does irregular spelling or pronunciation influence word recognition? Journal of Verbal Learning \& Verbal Behavior. 23, 383-404

Shallice, T., \& WarRINGTON, E. K. (1975). Word recognition in a phonemic dyslexic patient. Quarterly Journal of Experimental Psychologv, 27, 187-199.

Shallice, T., \& Warrington, E. K. (1987). Single and multiple component central dyslexic syndromes. In M. Coltheart, K. Patterson, \& J. C. Marshall (Eds.), Deep dyslexia (pp. 119-145). London: Routledge \& Kegan Paul.

SмIтH, F. (1971). Understanding reading: A psycholinguistic analisis of reading and learning to read. New York: Holt, Rinehart \& Winston.

Snodgrass, J. G., \& Mintzer, M. (1993). Neighborhood effects in visual word recognition: Facilitatory or inhibitory? Memory \& Cognition, 21, 247-266.

Spoenr, K., \& Smith, E. (1973). The role of syllables in perceptual processing. Cognitive Psychology, 5, 71-89.

Stanners, R. F., Neiser, J. J., Hernon, W. P., \& Hall, R. (1979). Memory representation for morphologically related words. Journal of Verhal Learning \& Verhal Behavior, 18, 399-412. 
Stanners, R. F., Neiser, J. J., \& Painton, S. (1979). Memory representation for prefixed words. Journal of Verbal Learning \& Verbal Behavior, 18, 733-743.

Stanovich, K., \& Bauer, D. W. (1978). Experiments on the spellingto-sound regularity effect in word recognition. Memory \& Cognition, 6, 410-415.

STERnBERG, S. (1969). The discovery of processing stages: Extensions of Donder's method. Acta Psychologica, 30, 276-315.

VAN ORDEN, G. C. (1987). A ROWS is a ROSE: Spelling, sound, and reading. Memory \& Cognition, 15, 181-198.

Van Orden, G. C., Johnston, J. C., \& Hale, B. L. (1988). Word iden- tification in reading proceeds from spelling to sound to meaning. Journal of Experimental Psychology: Learning, Memory, \& Cognition, 14, 371-385.

Van Orden, G. C., Pennington, B. F., \& Stone, G. O. (1990). Word identification in reading and the promise of subsymbolic psycholinguistics. Psychological Review, 97, 488-522.

WATers, G. S., Seidenberg, M. S., \& BruCK, M. (1984). Children's and adults' use of spelling-sound information in three reading tasks. Memory \& Cognition, 12, 293-305.

WofFIndin, G. C. (1995). Psycholinguistic stimuli sorting program [Computer program]. Las Vegas: World Commerce Ltd.
APPENDIX A

Stimulus Words

\begin{tabular}{ll} 
bag & gab \\
ban & nab \\
bat & tab \\
bus & sub \\
dam & mad \\
deep & peed \\
deer & reed \\
dew & wed \\
dim & mid \\
doc & cod \\
dog & god \\
draw & ward \\
evil & live \\
flow & wolf \\
gal & lag \\
gas & sag \\
gel & leg \\
golf & flog \\
gulp & plug \\
gut & tug \\
lap & pal \\
lever & revel \\
liar & rail \\
loop & pool \\
loot & tool \\
net & ten \\
nip & pin \\
pan & nap \\
par & rap \\
part & trap \\
pit & tip \\
ram & mar \\
rat & tar \\
raw & war \\
sit & tis \\
top & pot \\
\hline & \\
\hline
\end{tabular}

APPENDIX B Stimulus Nonwords

\begin{tabular}{ll} 
aig & gia \\
bik & kib \\
bap & pab \\
bov & vob \\
blin & nilb \\
cun & nuc \\
dut & tud \\
dalb & blad \\
deek & keed \\
dup & pud \\
erd & dre \\
fet & tef \\
fiza & azif \\
fleg & gelf \\
feek & keef \\
filb & blif \\
gen & neg \\
gite & etig \\
glip & pilg \\
gove & evog \\
kif & fik \\
lev & vel \\
learp & prael \\
lert & trel \\
mafe & efam \\
malp & plam \\
muj & jum \\
naz & zan \\
nuv & vun \\
pek & kep \\
plig & gilp \\
rej & jer \\
sut & tus \\
sek & kes \\
tef & fet \\
wof & fow \\
ris & \\
\hline & \\
\hline
\end{tabular}

(Manuscript received May 13, 1996; revision accepted for publication August 27, 1997.) 